\title{
Unemployment by Gender: Evidence from EU Countries ${ }^{\underline{4}}$
}

\author{
Dimitrios Bakas ${ }^{\mathrm{a}}$, Evangelia Papapetrou ${ }^{\mathrm{a}, \mathrm{b}, *}$ \\ ${ }^{\mathrm{a}}$ University of Athens, Department of Economics, 14 Evripidou Street, 10559, Athens, Greece \\ b Bank of Greece, Economic Research Department, 21 El. Venizelos Avenue, 10250, Athens, Greece
}

July 2013

\begin{abstract}
This paper applies panel unit-root tests that allow for structural breaks and cross-sectional dependence to examine the validity of hysteresis in gender unemployment rates and gender unemployment gap for a panel of 15 European countries. Addressing breaks, there is evidence to reject the null hypothesis of hysteresis for the unemployment rates and unemployment gap series. Allowing for both cross-sectional dependence and heterogeneous structural breaks this result is reverted and we fail to reject the null hypothesis of unit root.
\end{abstract}

Keywords: Gender Unemployment, Hysteresis, Panel Unit Root Tests, Structural Breaks, Cross Sectional Dependence

JEL Classification: C33, E24, J16

\footnotetext{
The authors are grateful to Professor Junsoo Lee for providing the GAUSS program codes. The first author would like to thank the Greek State Scholarships Foundation (IKY) for its financial support. The views expressed in this paper are those of the authors and not those of their respective institutions.

* Corresponding Author

Email addresses: dbakas@econ.uoa.gr (Dimitrios Bakas), epapapetrou@bankofgreece.gr (Evangelia Papapetrou)
} 


\section{Introduction}

The high and highly persistent unemployment rates across European countries and the US over the recent years have attracted a significant amount of both theoretical and empirical work. Economists suggest that major macroeconomic disturbances, such as a productivity slowdown, the steep rise in oil prices in the 1970s and changes in world interest rates could account for the rise and persistence of unemployment (Roed, 1997).

From a theoretical point of view there are two main hypotheses on unemployment behavior, hysteresis and the natural rate of unemployment. Hysteresis in unemployment implies that cyclical fluctuations have permanent effects on the level of unemployment due to labor market restrictions (Blanchard and Summers, 1986). By contrast, the natural rate of unemployment hypothesis characterizes unemployment as a mean reverting process, so shocks to the series have only temporary effects. These theories can be investigated by examining the order of integration of the unemployment rate. Level stationarity of unemployment (rejection of the unit root hypothesis) would support the natural rate of unemployment hypothesis whereas the presence of a unit root would imply that shocks affecting the series have permanent effects supporting the hysteresis hypothesis. In a seminal work, Blanchard and Summers (1986) use conventional unit root tests to examine the impact of hysteresis on unemployment and provide evidence of non-stationarity of unemployment in EU concluding that unemployment exhibits hysteresis, while, they find evidence of stationarity for the US.

Although the issue of unemployment persistence in EU has been studied extensively, the structure of unemployment by gender has received relatively little attention. Recently, there is renewed interest on the issue of gender unemployment. Hoynes et al. (2012) examine the labor market effects of the recent recession in the US and identify dramatic differences across various demographic groups, especially men and women. Peiro et al. (2012) analyze the relationship between male and female unemployment and the business cycle in the UK and the US providing evidence of a strong association between gender unemployment and cyclical factors. Ewing et al. (2005) stress the importance of analyzing the time series behavior of disaggregated unemployment rates and show, using nonlinear time-series techniques the differential effects of unanticipated shocks on unemployment rates of various demographic groups. Queneau and Sen (2008) present empirical evidence regarding unemployment dynamics for women and men in eight OECD countries using unit-root testing. They provide evidence of gender differences in 
unemployment dynamics only in Canada, Germany and the US and find that the degree of persistence of gender unemployment rates is rather low. Queneau and Sen (2012) using univariate unit-root tests find that US unemployment rates disaggregated by gender are characterized by the hysteresis hypothesis. Belloc and Tilli (2012), by examining the dynamics of unemployment rates by gender in Italian regions using unit root tests with structural breaks, show that the gender unemployment gap has narrowed.

However, most of these studies use univariate methods to explore the dynamics of unemployment rates for men and women. Nevertheless, it is has been recognized that the reliance on conventional univariate unit root tests, which exhibit very low power when the time period under consideration is short, makes the validity of these tests questionable. To address this problem, two different approaches are followed in the literature on testing the hysteresis hypothesis: first, the use of unit-root testing techniques that allow for the presence of structural breaks, such as the tests of Zivot and Andrews (1992) and Lee and Strazicich (2003) and, second, the application of panel unit root tests that allow for cross-sectional correlation in the error terms and help to avoid severe size distortions (O’Connell, 1999; León-Ledesma, 2002 Christopoulos and León-Ledesma, 2007; Liu et al., 2012). ${ }^{1}$ So the issue of hysteresis in unemployment by gender remains open.

The present paper contributes to the literature in two ways. First, it examines the nature of unemployment rates by gender for a panel of 15 European countries over the period 1977-2009 with the aim of gaining insights into the dynamics of unemployment by gender. To our knowledge the issue of unemployment persistence by gender is addressed for the first time in a panel framework analysis. We believe that the study of unemployment hysteresis by gender in EU countries provides potential valuable insights and is of major importance from a policy point of view. Effective macroeconomic policy requires the understanding of the possible effects that shocks could have on the male and female unemployment rates and highlights its role in mitigating unemployment.

Second, this paper addresses the issue of investigating the unemployment hysteresis hypothesis by gender for EU countries using panel unit root tests that allow for structural changes and also consider for cross-sectional dependence. Cross-sectional dependence is an

\footnotetext{
${ }^{1}$ For a survey on the theories of hysteresis and a review on theoretical and empirical evidence on hysteresis see among others Roed (1997), Lanzafame (2010) and Bakas and Papapetrou (2012).
} 
important characteristic in the analysis of macro and panel data models and can reflect global common shocks with heterogeneous impact across countries, such as the oil crises in the 1970s or the recent financial crisis and local spillover effects as a result of spatial or other forms of local dependencies (Pesaran and Tosetti, 2011; Sarafidis and Wansbeek, 2012). Allowing for cross-sectional correlation in the error terms we avoid severe size distortions in panel unit root testing and thus obtain more powerful results. Furthermore, we address possible heterogeneity across EU countries that may occur due to the different economic and labor market conditions in EU countries. This is achieved through the application of the Lagrange Multiplier (LM) panel unit root test of Im et al. (2010). This test initially makes use of a simple transformation method to obtain a test statistic invariant to both the location and the size of breaks in the level or trend of the series in the panel and thereafter it corrects for the presence of cross correlations in the innovations of the panel by applying the cross-sectional augmented procedure of Pesaran (2007) that is found to perform robustly under various specifications of cross-sectional dependence (Baltagi et al., 2007). ${ }^{2}$ Employing these panel unit root tests on the gender unemployment rates series we produce interesting results. When we account for level and trend break but do not address cross-sectional dependence, the null hypothesis of hysteresis is rejected for both gender unemployment rates and unemployment gap series. However, after allowing for cross-sectional dependence, the results are reverted and we fail to reject the null hypothesis of unit root, indicating that the gender unemployment series and the gender gap series in the EU-15 countries are not stationary with the presence of structural break.

The paper is organized as follows. The following section outlines the empirical methodology, whereas the next section presents the data and reports the empirical results. Finally, the last section provides the concluding remarks.

\section{Panel Unit Root Tests with Structural Breaks}

A number of recently developed panel unit root tests allow for the presence of structural breaks and cross-sectional dependence.

The Im et al. (2005) test statistic (hereafter ILT) is based on the panel extension of the Lee and Strazicich's (2004) LM test equation that allows for one shift in level and trend as follows:

\footnotetext{
2 This test depends only on the number of breaks in the series and, therefore, has significantly greater power than all previous panel tests (Im et al., 2010).
} 


$$
\Delta U_{i, t}=\delta_{i}^{\prime} \Delta Z_{i, t}+\phi_{i} \tilde{S}_{i, t-1}+\sum_{j=1}^{k} c_{i j} \Delta \tilde{S}_{i, t-j}+u_{i, t}
$$

where $U_{i, t}$ is the unemployment rate of country $i$ at time $t, \tilde{S}_{i, t}$ is the detrended unemployment rate series, $Z_{i, t}$ is a vector describing the breaks and $u_{i, t}$ is a white noise error term. Specifically, $Z_{i, t}=\left[1, t, D_{i, t}\right]^{\prime}$ expresses the case of a change in mean and $Z_{i, t}=$ $\left[1, t, D_{i, t}, D T_{i, t}^{*}\right]^{\prime}$ the case of a break in mean and trend. $D_{i, t}=1$ and $D T_{i, t}^{*}=t-T_{B i}$ for $t \geq T_{B i}+1$, and both are zero otherwise. $T_{B i}$ is the time period of the structural break for country $i$. The test statistic is based on the null hypothesis, $H_{0}: \phi_{i}=0$ for all $i$, against the (heterogeneous) alternative hypothesis, $H_{1}: \phi_{i}<0$ for some $i .^{3}$ The panel LM statistic is the average of univariate LM unit root $t$-statistic estimated for each individual $i$ :

$$
\bar{t}_{N, T}=\frac{1}{N} \sum_{i=1}^{N} \tilde{\tau}_{i, T}
$$

Then, the standardized ILT panel LM unit root test statistic is obtained as:

$$
L M_{\tilde{\tau}}=\frac{\sqrt{N}\left(\bar{t}_{N, T}-E\left(\tilde{\tau}_{i, T}\right)\right)}{\sqrt{V\left(\tilde{\tau}_{i, T}\right)}}
$$

where $E\left(\tilde{\tau}_{i, T}\right)$ and $V\left(\tilde{\tau}_{i, T}\right)$ are the expected value and variance of the individual $\tilde{\tau}_{i, T}$ statistic, respectively, as reported in Table 1 of Im et al. (2005). Thus, as $N, T \rightarrow \infty$, as long as $E\left(\tilde{\tau}_{i, T}\right)$ and $V\left(\tilde{\tau}_{i, T}\right)$ exist and $N / T \rightarrow k$, where $k$ is any finite constant, then $L M_{\tilde{\tau}} \rightarrow N(0,1)$ and the asymptotic distribution is not affected by the presence of structural breaks.

To address the problem of serious size distortions when the series are subject to breaks, Im et al. (2010) propose a LM (hereafter ILT*) panel unit root test that is invariant to the nuisance parameters. Following Lee and Strazicich (2009) the dependency of the test statistic on the nuisance parameter can be removed with the following transformation:

$$
\tilde{S}_{t}^{*}= \begin{cases}\frac{T}{T_{B}} \tilde{S}_{t} & \text { for } t \leq T_{B} \\ \frac{T}{T-T_{B}} \tilde{S}_{t} & \text { for } T_{B}<t \leq T .\end{cases}
$$

\footnotetext{
${ }^{3}$ The main advantage of this panel unit root test is that it allows for individual deterministic effects, heterogeneity in the autoregressive coefficients, heterogeneous structural breaks and lag lengths in the underlying equation and therefore controls for possible country heterogeneity in the panel of EU countries. For a recent survey on the literature on panel unit root tests, see among others, Breitung and Pesaran (2008).
} 
Using the transformed series, Im et al. (2010) formulate a test equation similarly to equation (1) by replacing $\tilde{S}_{i, t-1}$ with $\tilde{S}_{i, t-1}^{*}$. The transformed panel LM statistic is obtained as in equation (2) by averaging the relevant $t$-statistic $\left(\tilde{\tau}^{*}\right)$, and the standardized $I L T^{*}$ test is equivalent to equation (3). The estimated values of the average of the means and variances of $\bar{t}$ are reported in Table 2 of Im et al. (2010). Similarly, the standardized ILT* LM panel unit root test follows a standard normal distribution.

\section{Cross-Sectional Dependence Test}

The Cross-Sectional Dependence (hereafter CD) test of Pesaran (2004) is based on the average of pair-wise correlation coefficients $\left(\hat{\rho}_{i j}\right)$ of the OLS residuals obtained from the individual ADF regressions and is calculated as:

$$
C D=\sqrt{\frac{2 T}{N(N-1)}\left(\sum_{i=1}^{N-1} \sum_{j=i+1}^{N} \hat{\rho}_{i j}\right)}
$$

The CD statistic under the null of cross independence is distributed as a two-tailed standard normal distribution.

\section{Panel Unit Root Tests with Breaks and Cross Sectional Dependence}

The previous tests assumed no correlations across the error terms in the panel. To correct for the presence of cross-sectional dependence, Im et al. (2010) apply the cross-sectionally augmented procedure of Pesaran (2007) (hereafter CA-ILT*) that is found to be robust to the presence of several sources of cross-sectional dependence, such as the spatial form (Baltagi et al., 2007). The transformed testing regression augmented by the cross-section averages of lagged levels and first-differences of the individual series is:

$\Delta U_{i, t}=\delta_{i}^{\prime} \Delta Z_{i, t}+\phi_{i} \tilde{S}_{i, t-1}^{*}+g \bar{S}_{t-1}^{*}+h \Delta \bar{S}_{t}^{*}+\sum_{j=1}^{k} g_{i j} \Delta \bar{S}_{t-j}^{*}+\sum_{j=1}^{k} c_{i j} \Delta \tilde{S}_{i, t-j}+u_{i, t}$

with $\bar{S}_{t-1}^{*}=N^{-1} \sum_{i=1}^{N} S_{i, t-1}^{*} \quad$ and $\quad \Delta \bar{S}_{t}^{*}=N^{-1} \sum_{i=1}^{N} \Delta S_{i, t}^{*}=\bar{S}_{t}^{*}-\bar{S}_{t-1}^{*}$. Therefore, the $t$-statistic $\left(\tilde{\tau}^{* *}\right)$ on $\phi_{i}$ is used in order to construct the mean statistic $\bar{t}$ as in equation (2), which in turn can be used to construct the CA-ILT* test statistic equivalently to equation (3), 
which follows a standard normal distribution. ${ }^{4}$

\section{Data and Empirical Results}

\section{Data}

The empirical analysis employs annual data for the unemployment rates disaggregated by gender, namely, female $\left(u_{\text {female }}\right)$ and male $\left(u_{\text {male }}\right)$ unemployment rates for 15 European Union countries over 1977-2009, as well as for the total $\left(u_{\text {total }}\right)$ unemployment rate. ${ }^{5,6}$ Following similar studies, such as Christopoulos and León-Ledesma (2007), the analysis uses the logarithmic form of the unemployment rate, $U_{t}=\ln \left(u_{t}\right)$ and we also employ its logistic transformation, $U_{t}=\ln \left(u_{t} /\left(1-u_{t}\right)\right) .^{7}$ In line with Queneau and Sen (2010) we also utilize the gender unemployment gap, as measured by the difference between the female and male unemployment rates $\left(u_{\text {gap }}=u_{\text {female }}-u_{\text {male }}\right)$ and the ratio of the two rates $\left(u_{\text {ratio }}=\right.$ $\left.u_{\text {female }} / u_{\text {male }}\right)$. The unemployment series are obtained from the Annual Labor Force Statistics database of OECD.

\section{Empirical Results}

Table 1 presents the panel LM unit root test (ILT) and the transformed panel LM versions of the test with breaks in level $\left(I L T_{L}^{*}\right)$ and both in level and trend $\left(I L T_{L T}^{*}\right)$ that are invariant to the nuisance parameters and allow for the presence of heterogeneous structural breaks.

For the unemployment series $\left(U_{\text {total }}, U_{\text {male }}, U_{\text {female }}\right)$ and for the unemployment gap series ( $\left.U_{\text {gap }}, U_{\text {ratio }}\right)$, disregarding cross-sectional dependence, the ILT along with the transformed $I L T_{L}^{*}$ and $I L T_{L T}^{*}$ test statistic clearly indicate that the null hypothesis of hysteresis is rejected for all series, with the exception of female unemployment $\left(U_{\text {female }}\right)$ in the version of the test with a shift in level and trend. The results are invariant to the transformation of the

\footnotetext{
${ }^{4}$ The estimated critical values for the means and variances of $\bar{t}$ are provided in Table 3 of Im et al. (2010).

5 The analysis is restricted to this period in order to have a balanced data set, as annual data for gender unemployment series prior to 1977 are not available for all EU-15 countries.

${ }^{6}$ The 15 EU countries used are the following: Austria (AU), Belgium (BG), Denmark (DK), Finland (FI), France (FR), Germany (DE), Greece (GR), Ireland (IR), Italy (IT), Luxembourg (LU), Netherlands (NL), Portugal (PR), Spain (SP), Sweden (SW), United Kingdom (UK).

7 Since unemployment rate is a series that is bounded between 0 and 1, the conventional unit root tests are potentially unreliable in the presence of bounds (Cavaliere and $\mathrm{Xu}, 2013$ ). Thus, following the suggestion of Wallis (1987) we employ the logistic transformation for the unemployment rate.
} 
unemployment data.

Table 1 Panel LM Unit Root Tests with Structural Break

\begin{tabular}{lccccccc}
\hline & \multicolumn{3}{c}{ Logarithmic } & & \multicolumn{3}{c}{ Logistic } \\
\cline { 2 - 4 } \cline { 5 - 7 }$U_{\text {total }}$ & $I L T$ & $I L T_{L}^{*}$ & $I L T_{L T}^{*}$ & & $I L T$ & $I L T_{L}^{*}$ & $I L T_{L T}^{*}$ \\
\cline { 2 - 3 }$U_{\text {male }}$ & $-6.576^{*}$ & $-4.704^{*}$ & $-4.458^{*}$ & & $-6.549^{*}$ & $-4.741^{*}$ & $-3.108^{*}$ \\
$U_{\text {female }}$ & $-7.550^{*}$ & $-5.169^{*}$ & $-5.691^{*}$ & & $-7.528^{*}$ & $-4.691^{*}$ & $-6.847^{*}$ \\
& $-5.337^{*}$ & $-2.121^{*}$ & 0.635 & & $-5.258^{*}$ & $-2.006^{*}$ & 0.651 \\
$U_{\text {gap }}$ & & & & & & \\
$U_{\text {ratio }}$ & $-7.382^{*}$ & $-4.309^{*}$ & $-2.627^{*}$ & & $-7.158^{*}$ & $-4.579^{*}$ & -0.575 \\
\hline
\end{tabular}

Notes: ${ }^{*}$ indicates rejection of the null hypothesis at $5 \%$ significance level; the $5 \%$ critical value for the panel unit root test is -1.645 .

The issue of cross-sectional dependence is examined by applying the CD test (Table 2). The null hypothesis of no cross-sectional correlation among the EU panel members is strongly rejected at the $1 \%$ level of significance, for the three unemployment series and the two unemployment gap series, irrespective of the transformation of the unemployment data.

Table 2 Cross-Sectional Dependence Test

\begin{tabular}{|c|c|c|c|c|}
\hline & \multicolumn{2}{|c|}{ Logarithmic } & \multicolumn{2}{|c|}{ Logistic } \\
\hline & CD-test & Prob & CD-test & Prob \\
\hline$U_{\text {total }}$ & $16.95^{*}$ & 0.000 & $16.98^{*}$ & 0.000 \\
\hline$U_{m a l e}$ & $18.69^{*}$ & 0.000 & $18.73^{*}$ & 0.000 \\
\hline$U_{\text {female }}$ & $14.50^{*}$ & 0.000 & $14.53^{*}$ & 0.000 \\
\hline$U_{g a p}$ & $8.95^{*}$ & 0.000 & $8.90^{*}$ & 0.000 \\
\hline$U_{\text {ratio }}$ & $9.11^{*}$ & 0.000 & $9.40^{*}$ & 0.000 \\
\hline
\end{tabular}

Notes: ${ }^{*}$ indicates rejection of the null hypothesis at $5 \%$ significance level.

Given cross-sectional dependence, the panel LM versions of the tests that rely on both cross-sectional dependence and heterogeneous structural breaks are presented in Table 3. ${ }^{8,9}$

The $C A-I L T_{L}^{*}$ and the $C A-I L T_{L T}^{*}$ test statistic fail to reject the null hypothesis of unit root for the unemployment series disaggregated by gender, indicating that the gender unemployment series and the gender gap series in the panel of 15 European Union countries are not stationary with the presence of structural break. However, the results for the total

\footnotetext{
${ }^{8}$ We employ the one-break version of the panel LM tests of Im et al. (2005) and Im et al. (2010).

${ }^{9}$ The lag order of the tests is selected using the recursive $t$-statistic procedure with an upper bound of $k_{\max }=4$. All tests are based on a specification of the test equation with individual fixed effects at the $5 \%$ level of significance.
} 
unemployment $\left(U_{\text {total }}\right)$ are mixed and depend on the version of the test that is applied. Similar mixed findings are reported in the literature of examining the stationarity properties of total unemployment rates in EU countries, with studies supporting the hysteresis hypothesis (León-Ledesma, 2002) and others rejecting the unemployment hypothesis of non-stationarity in the panel of EU countries (Christopoulos and León-Ledesma, 2007).

Table 3 Panel LM Unit Root Tests with Structural Break and Cross-Sectional Dependence

\begin{tabular}{|c|c|c|c|c|}
\hline & \multicolumn{2}{|c|}{ Logarithmic } & \multicolumn{2}{|c|}{ Logistic } \\
\hline & $C A-I L T_{L}^{*}$ & $C A-I L T_{L T}^{*}$ & $C A-I L T_{L}^{*}$ & $C A-I L T_{L T}^{*}$ \\
\hline$U_{\text {total }}$ & 1.371 & $-3.819^{*}$ & 1.489 & $-2.494^{*}$ \\
\hline$U_{\text {male }}$ & 1.757 & 0.379 & 2.503 & -0.763 \\
\hline$U_{\text {female }}$ & 0.282 & -0.797 & 0.491 & -0.668 \\
\hline$U_{g a p}$ & 4.277 & -0.529 & 3.911 & 0.200 \\
\hline$U_{\text {ratio }}$ & 3.217 & -0.700 & 3.246 & -0.440 \\
\hline
\end{tabular}

Notes: ${ }^{*}$ indicates rejection of the null hypothesis at $5 \%$ significance level; the $5 \%$ critical value for the panel unit root test is -1.645 .

The evidence on the disaggregated results are invariant to the choice of the gender unemployment variables, that is unemployment rates by gender, and the two measures of gender unemployment gap and the transformation of the variables. Our findings show that unemployment rates across gender are characterized by hysteretic behavior, contrasting previous studies for OECD countries that use univariate methods (Queneau and Sen, 2008). Furthermore, we provide insights for differences in the behavior of the dissagragated unemployment series from the aggregate level of unemployment, confirming the earlier findings of Ewing et al. (2005) and Queneau and Sen (2012). Finally, the results imply that the gender unemployment gap remains persistent, confirming earlier findings for OECD countries (Queneau and Sen, 2010). Overall, the analysis suggests that cross-sectional dependence and the presence of structural breaks are critical aspects in explaining the behavior of the male and female unemployment rates and the unemployment gap and therefore should not be neglected in a panel analysis across European countries. ${ }^{10}$

\footnotetext{
${ }^{10}$ Similar findings for the sensitivity of the results to the presence of cross-sectional dependence and structural breaks are reported by Romero-Avila and Usabiaga (2009) for the time series properties of inflation rates and Snaith (2012) for the PPP puzzle.
} 


\section{Conclusions}

This paper examines the nature of male and female unemployment rates by using panel unit tests for a panel of 15 European countries. The panel unit root tests are invariant to both the location and the size of breaks and allow for both heterogeneous structural breaks and cross-sectional dependence. Accounting for breaks in level and trend, there is evidence to reject the null of hysteresis for the unemployment rates and unemployment gap series. However, this result is reverted when the test accounts for cross-sectional dependence. In this case, we fail to reject the null hypothesis of unit root. Given the indication of cross-sectional dependence in the panel of 15 European countries, we conclude that the gender unemployment rates and the gender gap series are not stationary with the presence of a structural break. Therefore, our findings suggest that there is evidence of persistence in the gender unemployment rates and the gender unemployment gap reflecting persistence inequalities in the European Union labor market that policy makers need to address.

\section{References}

Bakas, D. and E. Papapetrou (2012), "Unemployment in Greece: Evidence from Greek Regions,” Working Paper No. 146, Bank of Greece.

Baltagi, B. H., G. Bresson, and A. Pirotte (2007), "Panel Unit Root Tests and Spatial Dependence," Journal of Applied Econometrics, 22, 339-360.

Blanchard, O. J. and L. H. Summers (1986), "Hysteresis and the European Unemployment Problem," in NBER Macroeconomics Annual 1986, Cambridge, MA: MIT Press, 15-77.

Belloc, M. and R. Tilli (2012), "Unemployment by Gender and Gender Catching-up: Empirical Evidence from the Italian Regions,” Papers in Regional Science, forthcoming.

Breitung, J. and M. H. Pesaran (2008), “Unit Roots and Cointegration in Panels," in The Econometrics of Panel Data: Advanced Studies in Theoretical and Applied Econometrics, ed. by L. Matyas and P. Sevestre, Berlin: Springer Press.

Cavaliere, G. and F. Xu (2013), “Testing for Unit Roots in Bounded Time Series,” Journal of Econometrics, forthcoming.

Christopoulos, D. K. and M. A. León-Ledesma (2007), "Unemployment Hysteresis in EU Countries: What Do We Really Know About It?,” Journal of Economic Studies, 34, 80-89.

Ewing, B., W. Levernier, and F. Malik (2005), “Modeling Unemployment Rates by Race and Gender: A Nonlinear Time Series Approach,” Eastern Economic Journal, 31, 333-347. 
Hoynes, H., D. Miller, and J. Schaller (2012), “Who Suffers During Recessions,” Journal of Economic Perspectives, 26, 27-48.

Im, K., J. Lee, and M. Tieslau (2005), “Panel LM Unit-root Tests with Level Shifts,” Oxford Bulletin of Economics and Statistics, 67, 393-419.

Im, K., J. Lee, and M. Tieslau (2010), “Panel LM Unit-Root Tests with Trend Shifts,” Working Paper series, SSRN eLibrary.

Lanzafame, M. (2010), “The Nature of Regional Unemployment in Italy,” Empirical Economics, 39, 877-895.

Lee, J. and M. C. Strazicich (2003), "Minimum Lagrange Multiplier Unit Root Test with Two Structural Breaks,” The Review of Economics and Statistics, 85, 1082-1089.

Lee, J. and M. C. Strazicich (2004), "Minimum LM Unit Root Test with One Structural Break," Working Paper 04-17, Department of Economics, Appalachian State University.

Lee, J. and M. C. Strazicich (2009), "LM Unit Root Tests with Trend Breaks at Unknown Dates,” Mimeo.

León-Ledesma, M. A. (2002), "Unemployment Hysteresis in the US States and the EU: A Panel Approach”, Bulletin of Economic Research, 54, 95-103.

Liu, D. C., C. H. Sun, and P. C. Lin (2012), "Hysteresis Hypothesis in Unemployment and Labor Force Participation Rates: Evidence from Australian States and Territories,” Australian Economic Papers, 51, 71-113.

O’Connell, P. (1999), “The Overvaluation of Purchasing Power Parity”, Journal of International Economics, 44, 1-20.

Peiro, A., J. Belaire-Franch, and M. T. Gonzalo (2012), "Unemployment, Cycle and Gender," Journal of Macroeconomics, 34, 1167-1175.

Pesaran, M. H. (2004), “General Diagnostic Tests for Cross Section Dependence in Panels,” IZA Discussion Papers 1240, Institute for the Study of Labor (IZA).

Pesaran, M. H. (2007), “A Simple Panel Unit Root Test in the Presence of Cross-Section Dependence,” Journal of Applied Econometrics, 22, 265-312.

Pesaran, M. H. and E. Tosetti (2011), “Large Panels with Common Factors and Spatial Correlation,” Journal of Econometrics, 161, 182-202.

Queneau, H. and A. Sen (2008), “Evidence on the Dynamics of Unemployment by Gender,” Applied Economics, 40, 2099-2108.

Queneau, H. and A. Sen (2010), "On the Persistence of the Gender Unemployment Gap: Evidence from Eight OECD Countries,” Applied Economics Letters, 17, 141-145.

Queneau, H. and A. Sen (2012), "On the Structure of US Unemployment Disaggregated by Race, Ethnicity, and Gender,” Economics Letters, 117, 91-95. 
Roed, K. (1997), “Hysteresis in Unemployment,” Journal of Economic Surveys, 11, 389-418.

Romero-Avila, D. and C. Usabiaga (2009), "The Hypothesis of a Unit Root in OECD Inflation Revisited,” Journal of Economics and Business, 61, 153-161.

Sarafidis, V. and T. Wansbeek (2012), "Cross-Sectional Dependence in Panel Data Analysis," Econometric Reviews, 31, 483-531.

Snaith, S. (2012), “The PPP Debate: Multiple Breaks and Cross-Sectional Dependence,” Economics Letters, 115, 342-344.

Wallis, K. F. (1987), “Time Series Analysis of Bounded Economic Variables,” Journal of Time Series Analysis, 8, 115-123.

Zivot, E. and D.W. K. Andrews (1992), "Further Evidence on the Great Crash, the Oil-Price Shock, and the Unit Root Hypothesis,” Journal of Business and Economic Statistics, 10, 251-70. 